\title{
O conhecimento científico e tecnológico como evidência para políticas e atividades regulatórias em saúde *
}

\author{
Scientific and technological knowledge \\ as evidence for policies and regulatory \\ activities in health
}

\footnotetext{
* Este artigo é resultado de reflexões feitas para apresentação no $8 \underline{0}$ Seminário Temático A Contribuição da Epidemiologia para a Vigilância Sanitária, Projeto de Cooperação Técnica ISC/Anvisa.

1 Instituto de Saúde Coletiva/UFBa.

Rua Padre Feijó 29, Canela, 40110-170, Salvador BA. mauricio@ufba.br
}

Abstract In the last decades, significant changes in the occidental model of State have been observed. There is a clear trend towards reduction in the State direct role on social and economic activities. At the same time, an increasing participation in policy-making and regulation affairs is observed. In this context, there is a growing concern that scientific knowledge is necessary to subsidize the so complex State decision-making process in the large range of health-related matters. It is expected more effective decisions with great benefices to the population health and less social or economic costs. As consequence, it is increasing the participation of the State as consumer of the results of the scientific activities. The idea of an evidence-based policy-making has been used by the modern States, and in special in the health field this topic is receiving great attention. This paper aimed to discuss general aspects of the relationship between the decision making process in health, with emphasis in those related with regulatory affairs. After an overview of the literature on the topic, it discusses the relevance of this to the Brazilian SUS context.

Key words Scientific knowledge, Regulatory, Evidence-based policy, Health
Resumo Nas últimas décadas, têm-se observado mudanças na organização do modelo ocidental de Estado, com clara tendência de redução das suas atividades econômicas e sociais diretas. Ao mesmo tempo, percebe-se a ampliação de alguns dos seus papéis na elaboração de políticas e como regulador de uma série de parâmetros da vida social. Nesse contexto, consolida-se a noção de que são cada vez mais necessários conhecimentos científicos que fundamentem os processos de tomada de decisões. A idéia de política baseada em evidência foi apropriada pelo Estado moderno, $e$ na saúde vem recebendo especial atenção. Avaliase que, assim procedendo, se ampliam as chances de se tomar decisões mais efetivas, trazendo maiores benefícios à saúde da população, com menos custos econômicos ou sociais. Essa nova abordagem torna o Estado um crescente consumidor dos resultados da atividade científica. $O$ objetivo deste ensaio é discutir alguns aspectos da relação entre o processo de produção do conhecimento científico e os processos gerais de tomada de decisões na área da saúde, com maior ênfase naqueles relacionados às atividades regulatórias. Após rever a literatura recente sobre o tema, comenta-se a importância dessa discussão no contexto do SUS no Brasil.

Palavras-chave Conhecimento científico, Regulação, Políticas baseadas em evidência, Saúde 
A pesquisa em saúde vem de épocas remotas, porém assume a sua forma moderna a partir do século 19. Na França, os estudos de Claude Bernard na medicina experimental, de Pasteur na bacteriologia, de Villermé na epidemiologia social, ou de Pierre Louis na avaliação das terapêuticas; e, na Inglaterra, os estudos de Snow na epidemiologia e os de William Farr na demografia e saúde são exemplos de programas de pesquisa seminais na estruturação da investigação científica em saúde do século 19, a qual atingirá sua maturidade no decorrer do século seguinte. Embora a pesquisa científica seja muito freqüentemente celebrada como expressão da grandeza e da criatividade do espírito humano, simultaneamente ao seu processo de estruturação foi se tornando claro o seu papel como parte do processo de desenvolvimento econômico e social das nações, levando-a aos poucos a evoluir de uma ação pessoal para uma atividade institucional e que exige planejamento, investimentos e organização para sua concretização. Paulatinamente, deixa de ser uma atividade independente realizada por indivíduos brilhantes (Darwin, por exemplo, financiou todo o seu programa de pesquisa com recursos próprios) para tornar-se uma atividade estabelecida em centros acadêmicos ou instituições independentes organizadas com esse propósito, realizada por profissionais treinados e financiada pelo Estado ou por grandes corporações.

Nas últimas décadas, têm-se observado mudanças significativas na organização do modelo ocidental de Estado, com clara tendência de redução das suas atividades econômicas e sociais diretas. Por outro lado, observam-se crescentes discussões sobre a ampliação do seu papel na elaboração de políticas, legislações e normas regulatórias; como conseqüência, consolida-se também a noção de que se fazem cada vez mais necessários conhecimentos científicos que fundamentem os processos de tomada de decisões dos governos, inclusive no campo da saúde. A expectativa é de que as decisões, uma vez tomadas, tenham maior efetividade, trazendo maiores benefícios à saúde da população, e impliquem menos custos, sejam estes econômicos ou sociais. Ao adotar tal estratégia, o Estado se posiciona como um crescente consumidor dos resultados da atividade científica. Para exemplificar o uso dessa estratégia como política de governo, podemos referir documento recente elaborado para o gabinete do governo inglês, que se utiliza claramente da noção de estabelecimento de evidências como elemento central para a proposta de modernização dos seus processos de formulação de decisões em todas as áreas de atuação governamental (Strategic Policy Making Team, 1999).

Associada a essa crescente consciência de que decisões referentes às políticas e ações governamentais, dada a sua complexidade e as suas múltiplas implicações, devem ser cada vez mais fundamentadas em evidências científicas, verifica-se a crescente participação do Estado como formulador, financiador e, muitas vezes, executor das políticas e atividades de desenvolvimento científico e tecnológico (C\&T). No tocante ao campo da saúde, em muitas sociedades existe o consenso de que o Estado é, em última instância, o responsável pelas condições de saúde da população e, assim, responsável direto ou indireto pela organização dos serviços de saúde e pelas atividades de prevenção da doença e promoção da saúde. Essas responsabilidades e a preocupação de tornar os sistemas de decisões mais qualificados para cumpri-las adequadamente têm levado os governos a se situarem entre os principais usuários dos produtos das atividades de desenvolvimento científico e tecnológico no campo da saúde. Não por acaso, em muitos países, as atividades de pesquisa em saúde têm um grau de diferenciação com relação às demais atividades de C\&T, estando direta ou indiretamente vinculadas aos seus ministérios da Saúde. O objetivo deste ensaio é discutir alguns aspectos da relação entre o processo de produção do conhecimento científico e os processos gerais de tomada de decisões no campo da saúde, mais especificamente aqueles relacionados com as políticas e atividades regulatórias.

\section{Políticas de saúde baseadas em evidências}

Desde tempos remotos, usam-se conhecimentos para organizar atividades de saúde. Com o desenvolvimento da ciência, o conhecimento científico passa a ter maior importância nesse processo. Porém, deve-se ter em mente que, como acontece em vários outros campos da ação humana, no processo de elaboração de decisões no campo da saúde o conhecimento científico é apenas um dos componentes, pois parte deste processo não é e, possivelmente, nunca será cientificamente fundamentado. Em épocas recentes, existe o entendimento de que o compo- 
nente científico deva ser ampliado, na expectativa de que as decisões contenham um maior grau de certeza, atingindo os objetivos propostos e, como conseqüência, resultando, em última instância, em melhorias efetivas das condições de saúde das populações.

Para exemplificar os impasses enfrentados por aqueles que estão encarregados das formulações políticas em saúde, tomemos o caso recente de uma comissão criada pelo parlamento inglês para estudar a questão das desigualdades em saúde na Inglaterra e propor ações (Acheson, 1998). Essa comissão destacou, entre as suas conclusões, que há, por um lado, fortes evidências do papel das condições sociais como determinante das desigualdades em saúde. Por outro lado, porém, há escassas evidências de que políticas sociais e de saúde que se supõe redutoras de tais desigualdades sejam realmente efetivas (Macintyre et al., 2001). Um estudo recente, que busca avaliar os efeitos das recomendações do relatório Acheson (1998) nas políticas e na situação atual das desigualdades em saúde naquele país, recomendou que as investigações nesse campo deveriam se deslocar de estudos dos determinantes para estudos de avaliação das políticas destinadas a reduzir tais desigualdades (Exworthy et al., 2002). Em uma outra perspectiva, estão as críticas aos aspectos conceituais que, na essência, questionam os paradigmas utilizados na epidemiologia da desigualdade, os quais, não por acaso, servem de referência conceitual para o relatório Acheson (1998). Essas críticas são taxativas em concluir que políticas derivadas de tais conhecimentos tendem à inefetividade (Scrambler \& Higgs, 1999).

Discuta-se agora um determinante de saúde mais específico, tal qual é o hábito de fumar cigarros. Desde a década de 1950, acumulamse evidências de efeitos perniciosos desse hábito sobre a saúde, não existindo nenhuma dúvida sobre o seu papel como fator de risco para cânceres (de pulmão e de outros órgãos), doenças pulmonares obstrutivas crônicas, doenças cardiovasculares etc. Como conseqüência, reduz a expectativa de vida, aumenta a carga de morbidade e os custos da atenção à saúde. Não por acaso, o hábito de fumar está situado entre os fatores de risco que, isoladamente, têm os maiores efeitos negativos sobre a saúde (Ezzati et al., 2002). Entretanto, no tocante ao combate desse hábito, os conhecimentos epidemiológicos, acima referidos, possibilitaram apenas a formulação de ações no plano individual e de caráter educativo. Somente quando pesquisadores de outras disciplinas deram início a investigações sobre temas como: os determinantes do hábito de fumar, o papel ativo da indústria do fumo no marketing para promover o hábito e no descrédito de investigações que demonstravam os efeitos nocivos do fumo, os aspectos econômicos envolvidos da produção e comercialização do fumo e do cigarro, os custos sobre o sistema de saúde etc., tornou-se possível elaborar um quadro de referência mais completo para situar as políticas de combate ao fumo e mobilizar setores mais amplos da sociedade no sentido da elaboração destas políticas e ações mais abrangentes (que agora incluem ações legislativas, fiscais, judiciais etc.). Apesar disto, só recentemente é que essas ações começam a ser implementadas, porém ainda com um alto grau de complacência de vários setores da sociedade e com forte oposição da indústria do fumo, tornando-as, na prática, pouco efetivas no sentido de ocasionar reduções mais significativas no hábito de fumar (Saloojee $\& \mathrm{Da}$ gli, 2000; Barnoya \& Glantz, 2002).

Esses dois exemplos servem para que se generalize um dilema com freqüência vivenciado. Em alguns momentos, faltam conhecimentos para que decisões sejam tomadas; e em outros, embora existam conhecimentos suficientes, não há, por motivos diversos, a capacidade ou a vontade de tomá-las e implementar as ações delas decorrentes. Se isso nos faz refletir sobre os complexos relacionamentos entre os processos de tomada de decisões e a disponibilidade do conhecimento científico, não deve desestimular a crença na importância do conhecimento quando o desejo é a elaboração de políticas e ações de saúde que tenham maiores chances de se tornar efetivas e que, como conseqüência, tragam maiores benefícios para a saúde da população.

A elaboração de políticas e outras atividades de tomada de decisões em ambientes democráticos são processos complexos, dos quais participam vários atores da vida social carreando os seus diversificados interesses. $\mathrm{O}$ conhecimento científico e seus detentores somam-se aos demais atores, mas, freqüentemente, não estão na hegemonia desses processos. Além disso, muitas vezes, decisões necessitam ser tomadas em momentos em que apenas se dispõe de escassas evidências. É claro que a produção do conhecimento científico nunca será definida apenas pelo imediatismo das necessidades de elaboração de políticas. O sistema científico é 
relativamente independente dessas necessidades mais imediatas e seu objetivo primário é produzir o conhecimento e fazê-lo circular e difundir-se em redes, onde estará sujeito a escrutinações de diversas ordens. Assim, aqueles que necessitam tomar decisões podem, eventualmente, extrair do "estoque" de conhecimentos aquilo que é utilizável com relação aos problemas que está solucionando ou às proposições que está elaborando. A não disponibilidade, nesse "estoque", de conhecimentos que sirvam para a solução de um dado problema pode servir de estímulo para a realização de novas pesquisas que venham a auxiliar, no futuro, a solução desse problema ou de outros similares (Haney et al., 2003).

O processo de transformar o conhecimento em evidência alimentadora de uma decisão é complexo e nunca totalmente científico, sendo permeado por diferentes interpretações e valorações do conhecimento existente, da mesma forma que todo o processo de produzir e disseminar conhecimentos está mediado por relações que se estabelecem no interior da comunidade científica e desta com os vários setores e interesses da sociedade. Com relação a uma mesma questão, no "estoque" podem existir conhecimentos diversificados, produzidos por diferentes disciplinas, muitas vezes com diferentes abordagens teóricas e em diferentes contextos históricos e geográficos. Extrair e utilizar o conhecimento em "estoque" é um processo complexo e não existe uma forma única de fazê-lo, podendo variar desde formas não sistemáticas até formas mais sistemáticas e com metodologias estruturadas. Não por acaso, em épocas recentes, vêm sendo desenvolvidos os métodos de revisão sistemática (entre os quais se inclui a meta-análise), através dos quais se busca de forma metodologicamente organizada (quando possível, quantitativamente) dar sentido ao conhecimento "estocado" em torno de uma dada questão.

O processo de tomada de decisões pode identificar necessidades de novos conhecimentos. Essas necessidades, quando satisfeitas, alimentam o "estoque" de conhecimentos, e podem ter nexos mais imediatos com os processos de decisões. Não por acaso, os estudos de avaliação, pelas possibilidades de sua aplicação mais imediata na formulação de decisões em saúde, constituem-se em uma estratégia de produção de conhecimento que tem sido crescentemente valorizada pelos tomadores de decisões, pois são particularmente úteis nos pro- cessos de redefinição e ajuste de políticas já existentes. Deve-se estar atento para o fato de que qualquer conhecimento, mesmo aquele com um grau maior de aplicabilidade em curto prazo, para receber o status de conhecimento científico e entrar no "estoque" tem de cumprir certas etapas. O núcleo desse "estoque" são as denominadas revistas científicas, a despeito de, na atualidade, serem algumas delas publicadas exclusivamente on-line, sem a tradicional versão em papel. Porém, todas partilham de algumas características comuns, sendo a mais fundamental delas a revisão por pares (peer-review) de todo material científico nelas publicados.

À medida que cresce a importância do conhecimento científico nos processos de formulação de decisões, este começa a se confrontar com outras posições e interesses envolvidos no citado processo, que, ao terem sua influência diminuída ou os seus interesses contrariados, passam a se constituir em forças de oposição ao conhecimento científico ou à própria ciência (Rosentock \& Lee, 2002). Nessa direção, por exemplo, os avanços recentes no conhecimento científico, no campo da reprodução humana, têm se confrontado com dogmas religiosos com forte influência nas políticas dessa área. Políticas no campo da interrupção da gravidez ou do controle da natalidade têm sofrido a influência de diferentes correntes religiosas, as quais têm mantido posições dogmáticas que contrariam evidências consolidadas na ciência. Uma outra área sujeita a grandes controvérsias entre as dimensões científicas e não-científicas é a área ambiental, campo em que ocorrem imensas divergências, desta vez envolvendo governos, indústrias, grupos organizados da sociedade civil e a comunidade científica. $\mathrm{O}$ caso do aquecimento da Terra é um bom exemplo a ser considerado. Acumulam-se evidências de que a temperatura terrestre tem aumentado de maneira não controlada e a manutenção dessa tendência poderá se constituir em um sério problema para a vida no planeta nos próximos séculos. Essas evidências levaram, entre outras ações, à elaboração do tratado de Kyoto, protocolo intergovernamental com grande suporte dos grupos ambientalistas e que tem por objetivo obter o compromisso de cada país signatário para o desenvolvimento de políticas que reduzam a emissão de $\mathrm{CO}_{2}$ nos seus territórios. Espera-se, dessa forma, reduzir a tendência de aumento da temperatura do planeta. Até o momento, os EUA, um dos países que mais contri- 
buem para tais emissões, recusaram-se a assinar o protocolo, sob a justificativa de que os potenciais efeitos positivos que resultariam do cumprimento do tratado seriam menores que o esperado e não justificariam possíveis efeitos negativos na economia (Leaf et al., 2003).

Interesses mais imediatos de grupos econômicos podem também se constituir em motivação para contraposições ao conhecimento científico. As indústrias e seus representantes têm, de várias maneiras, se reorganizado no sentido de encontrar mecanismos que contrariam normas estabelecidas e as expectativas da sociedade organizada (Abraham \& Lewis, 2002). Tem sido fartamente documentado o caso da indústria de cigarros, que utiliza imensas quantidades de recursos no sentido de criar descrédito de qualquer conhecimento científico ou mesmo de pesquisadores envolvidos na produção dos conhecimentos que contribuem para demonstrar os efeitos nefastos do cigarro (Ong \& Glantz, 2001; Barnoya \& Glantz, 2002). Para enfrentar essas tentativas de contraposição ou de descrédito do conhecimento científico, tem-se reafirmado a necessidade de fortalecer os mecanismos que ampliem o financiamento governamental das pesquisas científicas, que verifiquem a integridade e a independência daqueles envolvidos na produção do conhecimento científico e que criem barreiras no processo de produção e circulação do conhecimento, tentando-se evitar que conhecimentos eivados de interesses particulares ganhem o mesmo status que aqueles independentemente produzidos.

É também importante enfatizar a proteção aos próprios pesquisadores, os quais podem sofrer constrangimentos pessoais quando produzem resultados que afetam interesses de grupos econômicos. Nessa área, vale relatar uma experiência recentemente vivenciada pelo autor. Um grupo de investigadores estudou os efeitos adversos de uma vacina administrada em campanhas de massa no país e produziu relatório técnico que veio a subsidiar decisão do Programa Nacional de Imunização (PNI/FUNASA/MS) de não mais utilizar a referida vacina. Após terem tomado conhecimento da decisão, executivos da indústria produtora solicitaram cópia do relatório técnico, traduziram-no para o inglês e, com o apoio de um consultor por eles contratados, produziram uma análise crítica do relatório. Com o claro intuito de desacreditá-lo, teceram críticas contundentes aos métodos utilizados no estudo e até levantaram suspeitas de falsificação dos dados utilizados. Com base no parecer do consultor, o executivo-chefe da empresa escreveu carta aos autores do relatório, ameaçando-os em caso de virem a publicar os resultados em alguma revista científica. Após certificação da qualidade científica do relatório, feita por pesquisadores independentes que se prontificaram a revê-lo, o artigo foi submetido, aceito e publicado em uma revista de circulação internacional (Cunha et al., 2002), passando a constituir-se naquilo que a empresa produtora a todo custo tentou evitar a primeira evidência científica dos efeitos adversos dessa cepa de vacina.

\section{Atividades regulatórias no campo da saúde}

É função do Estado moderno, através dos seus poderes legislativo e normativo, regular e monitorar os potenciais efeitos adversos de uma série numerosa e complexa de exposições naturais ou artificiais, diretamente relacionadas ao sistema de saúde (medicamentos, vacinas, equipamentos etc.) ou que podem ter implicações na saúde dos indivíduos ou das populações (qualidade da água e dos alimentos, exposição ambiental a poluentes diversos etc.) (Buffler \& Kyle, 1996). Assim, cabe ao Estado definir questões tão diversas como: a) autorizar o uso de cada medicamento ou vacina, os parâmetros de teste que garantam a sua segurança e eficácia, os padrões da sua produção etc.; b) definir níveis máximos aceitáveis para diferentes tipos de poluentes, aditivos alimentares, inseticidas, radiações etc.; c) definir parâmetros para uma extensa série de equipamentos e tecnologias usadas pelo sistema de saúde; d) definir parâmetros e meios para o monitoramento dos efeitos adversos de toda a imensa gama de recursos tecnológicos utilizados pelo sistema de saúde.

Os exemplos são infinitos em termos de eventos em que a falta de regulação adequada gerou prejuízos imensos para a população humana. Tome-se o exemplo histórico da talidomida. Medicamento utilizado no tratamento da hanseníase (Oliveira et al., 1999), foi também usado, há algumas décadas, no tratamento da náusea da gravidez. Foi necessária a ocorrência de milhares de casos graves de teratogenia, em muitos países, antes que os órgãos de saúde responsáveis pelo controle dos medicamentos suspendessem a indicação da sua utili- 
zação por mulheres grávidas (Botting, 2002). Fatos como estes, pela sua importância em termos da magnitude dos danos causados à saúde da população, ficaram na consciência coletiva e estão na base dos movimentos pelo desenvolvimento de mecanismos mais eficientes e que protejam a sociedade de forma ágil e efetiva, contra esses tipos de eventos indesejáveis. Porém, antes de tudo, tiveram efeitos marcantes no tocante ao desenvolvimento da consciência e das preocupações coletivas com relação aos potenciais riscos relacionados a cada nova exposição que o avanço científico e tecnológico vem tornando possível.

Não por acaso, no rastro de histórias dramáticas como os ocorridos em conseqüência dos efeitos negativos dos Raios-X ou da talidomida, a introdução de novas tecnologias que produzem radiações ou de novos medicamentos tem sido precedida de grande cautela. Estudos têm sido feitos desde a introdução da ultrasonografia, buscando identificar e existência de possíveis efeitos relacionados a sua aplicação no acompanhamento do desenvolvimento fetal (Brent et al., 1991). Até o momento, não são completamente satisfatórios os estudos sobre os efeitos das radiações liberadas pelos celulares (United States General Accounting Office, 2001) ou pelas redes de transmissão de energia em alta voltagem (Ahlbom, 2001). Porém, apesar desses cuidados, a literatura científica está cheia de relatos de efeitos danosos observados após a aprovação e liberação de produtos pelos órgãos regulatórios. Pode-se citar o exemplo recente de uma vacina contra o rotavírus, liberada para comercialização nos EUA após passar pelo rigoroso processo da agência reguladora de medicamentos daquele país - a Food and Drug Administration (FDA). Algum tempo após o início de sua comercialização, apareceram relatos de aumento do número de casos de intussepção intestinal naquele país, levantando-se a hipótese de que tais eventos poderiam estar associados ao uso da vacina. Em seqüência, estudos rigorosos verificaram risco de intussepção intestinal até 20 vezes maior em crianças vacinadas com relação às não vacinadas (Murphy et al., 2001). O fato de que riscos daquela magnitude não tenham sido observados nos estudos da fase pré-regulatória a que a vacina obrigatoriamente foi submetida é razão para preocupações e questionamentos dos métodos de avaliação pré-regulatórios que se têm utilizado.

A história da regulação dos parâmetros de potabilidade da água fornece um exemplo inte- ressante da relação entre as intervenções regulatórias e um componente fundamental para a existência da vida humana (Raucher, 1996). As normas regulatórias da água se iniciam (nos países hoje desenvolvidos) com a preocupação de evitar a contaminação bacteriológica da água potável, pois esta era então o veículo responsável pela disseminação de uma série de doenças infecciosas com grande impacto na saúde da população. Tais ações obtiveram alto grau de sucesso na prevenção dessas doenças. Com essas conquistas, as preocupações com os aspectos bacteriológicos decrescem, ao mesmo tempo em que crescem as preocupações com as substâncias químicas natural ou artificialmente introduzidas na água, sobre as quais começam a aparecer evidências de seus efeitos negativos sobre a saúde, principalmente no papel de cancerígenos. Com a redução da importância das doenças infecciosas nos países desenvolvidos, as novas normas regulatórias centram-se em estabelecer padrões seguros de potabilidade com relação aos contaminantes químicos. Mais recentemente, no bojo da reemergência das doenças infecciosas, observam-se surtos de algumas dessas doenças, associados ao uso até mesmo de águas potáveis com o adequado tratamento (e.g. surtos de diarréia atribuídos ao Criposporidium parvum), indicando novamente a necessidade de revisão dos padrões de proteção com relação aos agentes bacteriológicos. No tocante aos contaminantes químicos, o conhecimento continua avançando no sentido de demonstrar que alguns destes, mesmo em níveis extremamente baixos de contaminação, podem estar associados a riscos de cânceres, estimulando as pressões para que sejam reduzidos os níveis aceitáveis de tais contaminantes. Veja-se agora o caso da história do arsênico como contaminante da água. Usado como medicamento no passado, o arsênico foi posteriormente reconhecido como um poderoso cancerígeno. Infelizmente, por estar presente na composição de muitas rochas, ele é um contaminante natural de grande parte da água subterrânea da Terra (Nordstrom, 2002). Até há poucos anos, o nível máximo de contaminação aceito era de $0,05 \mathrm{mg} / \mathrm{L}$, porém em época recente esse nível baixou para $0,01 \mathrm{mg} / \mathrm{L}$, constituindo-se no atual padrão internacional (Smith $e t$ al., 2002). Estima-se que viver com base em fontes de água com um nível de contaminação de $0,05 \mathrm{mg} / \mathrm{L}$ aumenta em $1 \%$ o risco de câncer, porém o nível de $0,01 \mathrm{mg} / \mathrm{L}$ não é garantia da ausência de riscos. Como esse é um tipo de ex- 
posição que afeta toda uma população, os seus riscos atribuíveis são elevados, mesmo que os riscos relativos sejam baixos. Porém, a decisão de mudar os níveis aceitáveis de contaminação tem tido fortes oponentes, pelas implicações econômicas no aumento dos custos de tratamento da água. Um fato dramático relacionado aos níveis de arsênico na água vem ocorrendo em Bangladesh (Smith et al., 2000). Na década de 1970, como parte do esforço para controle da diarréia e outras doenças de transmissão fecal, organizações internacionais estimularam a construção de poços artesianos, em substituição às fontes de água superficiais para suprimento de água potável. Na época, não se verificou o grau de contaminação com arsênico da água oriunda desses poços, pois o papel desse contaminante era de preocupação secundária. Anos após, inquéritos em vários locais daquele país têm registrado altas prevalências de manifestações da intoxicação pelo arsênico, e hoje estima-se que mais de 30 milhões de pessoas são supridas com água que apresentam níveis até 300 vezes superiores aos níveis recomendados internacionalmente $(0,01 \mathrm{mg} / \mathrm{L})$.

A questão regulatória é um subtema na discussão mais ampla das relações entre o conhecimento científico e os processos de decisão do Estado. No entanto, a qualidade do conhecimento para as atividades regulatórias em saúde deve possuir algumas características peculiares, pois esses conhecimentos irão alimentar decisões que pretendem ter um alto grau de precisão, tais como: usar ou não um medicamento ou vacina; definir o nível máximo aceitável de um poluente ambiental ou de um dado elemento na água ou nos alimentos etc. Normas reguladoras, muitas vezes, consistem em definir limites precisos e que dividem níveis contínuos de exposição entre o risco e o não-risco. Legislações e normas mal-elaboradas podem significar o suporte do Estado a condutas errôneas, com prejuízos para os seus cidadãos no plano da saúde, da moral ou da economia.

\section{Pontos para ampliar a discussão}

Embora saiba-se que os processos legislativos e normativos são processos complexos e que envolvem elementos diversos, sabe-se também que têm maior chance de chegar a resultados inadequados quando fundados em conhecimentos científicos precários. Assim, a utilização de ações ou tecnologias de saúde inefetivas ou que venham a causar efeitos nocivos em seus usuários, ou a exposição dos indivíduos a condições ambientais com fortes efeitos patogênicos são exemplos de situações pouco aceitáveis nas sociedades modernas. Por interferirem no cotidiano das pessoas, as questões regulatórias em saúde têm estado diretamente vinculadas ao conceito de cidadania que se desenvolve nas sociedades ocidentais modernas (Abraham \& Lewis, 2002).

É importante observar que a discussão recente na área das relações entre conhecimento científico e formulação de decisões no campo da saúde tem sido apresentada em uma perspectiva pragmática, a qual desconsidera as divergências conceituais existentes. Não por acaso, há um crescente esforço para se entender as diferentes possibilidades de inter-relacionamento entre o conhecimento científico e as formulações de políticas e de ações em saúde (Niessen et al., 2000; Hanney et al., 2003; Samet, 2000). Entretanto, parece limitada a idéia prevalente de que as abordagens de cuidado à saúde baseadas em evidências podem ser descritas como políticas de saúde e prestação de serviços de saúde fundadas em provas sistematicamente coletadas sobre o efeito de intervenções relacionadas à saúde e originárias das ciências sociais e da saúde (Niessen et al., 2000). Para os complexos processos de decisão em saúde, tal como a formulação de políticas, necessita-se de conhecimentos relacionados às condições de saúde, aos seus determinantes, a efetividades das ações propostas etc. e, antes de tudo, é necessário penetrar nos debates conceituais que permeiam as diferentes concepções do processo de saúde-doença nas diferentes sociedades humanas.

Ao rever as relações entre conhecimento científico e decisões em saúde de uma perspectiva histórica, percebe-se que elas vêm sendo permeadas por divergências conceituais relevantes e que ao nos retermos apenas no debate atual, se perde a capacidade de entender essas divergências, com tendência de minimizá-los. Nesse sentido, quando se desloca do conhecimento sobre as práticas sanitárias em direção ao conhecimento dos determinantes das doenças, verifica-se que as divergências se ampliam. Em um extremo, o modelo biomédico dominante tende a focar as causas das doenças nos mecanismos biológicos internos do organismo humano ou no máximo nas causas proximais (germes, fatores ambientais específicos, ou prática de determinados comportamentos) e que 
se expressariam por distúrbios nas funções orgânicas normais; no outro extremo, há modelos que identificam as causas das doenças na estrutura da sociedade (Breilh, 1989). Entre esses extremos, permeiam-se diversos outros modelos de causalidade (Frohlich et al. 2001). Não por acaso, as políticas de saúde atuais gravitam em torno do primeiro grupo de modelos de causalidade. Tesh (1988), analisando detidamente a questão, conclui que as políticas de saúde se utilizam de três modelos básicos de monocausalidade: a teoria do germe, a teoria ambiental e a teoria comportamental. Isto significa que o papel dos determinantes sociais, com todo o acúmulo de evidências nesta direção, é desconsiderado no momento da formulação das políticas de saúde na maioria das sociedades.

Um bom exemplo dessa questão pode ser discutida com relação à ressurgência da tuberculose nos dias atuais (Barnes, 1995; 2000; Gandy \& Zumla, 2002; Fairchild \& Oppenheimer, 1998). Na era pré-bacteriana, predominava uma visão de determinismo social que, claramente, enfatizava os vínculos da tuberculose com a pobreza; embora outras causas como aquelas de ordem moral (e.g. alcoolismo) eram também postas em cena. No entanto, com a passagem para a era bacteriana, no final do século 19, as concepções relacionadas com a determinação social são descartadas. É interessante observar que isso aconteceu apesar de os avanços na bacteriologia somente terem trazido alguma contribuição efetiva para o tratamento da tuberculose mais do que seis décadas após a descoberta da sua etiologia bacteriana, com o advento da estreptomicina na década de 1940. Em épocas recentes, apesar das demonstrações de que a ressurgência da tuberculose em muitos países, mesmo desenvolvidos, tem também vínculos com a ordem social, pois são conseqüentes em última instância das políticas neoliberais e do agravamento das condições de vida dos grupos mais pobres, as suas políticas de controle, difundidas pelos organismos internacionais e efetivadas na políticas nacionais de saúde, centram suas ações no tratamento dos doentes, enquanto as pesquisas priorizam o desenvolvimento de novos medicamentos e novos recursos diagnósticos.

\section{Conclusões e implicações para o contexto brasileiro}

Nas sociedades ocidentais modernas, o exercício do poder de formulação de políticas e de decisões relacionadas à saúde está centrado no Estado, que de forma crescente necessita de conhecimentos técnico-científicos atualizados para o exercício a contento desta tarefa. No contexto brasileiro, seguindo essa tendência, o processo de consolidação do SUS e a conseqüente ampliação do setor público nas funções de suprir as necessidades de saúde da população e de regular os fatores relacionados com a saúde têm levado os organismos encarregados dessa tarefa a ampliar suas demandas por conhecimentos científicos. A realização da I Conferência Nacional de Ciência e Tecnologia em Saúde, em 1994, foi um marco nesse processo (Brasil, 1994) por aprofundar o debate sobre C\&T no interior das discussões sobre o SUS. A organização institucional do Ministério da Saúde tem refletido essa maior preocupação com a geração e consumo do conhecimento científico e tecnológico. No governo passado, foi criado o Departamento de Ciência e Tecnologia e o atual governo criou a Secretaria de Ciência, Tecnologia e Insumos Básicos, à qual o Departamento de Ciência e Tecnologia ficará agora subordinado. Vale ressaltar que a busca de fortalecimento técnico e político dos vários órgãos encarregados da gestão e regulação do SUS faz necessariamente crescer a demanda por conhecimentos científicos e tecnológicos. A criação de duas agências regulatórias específicas, a Agência Nacional de Vigilância Sanitária (Anvisa) para a área de medicamentos, alimentos e ambiente e a Agência Nacional de Saúde (ANS), para a área dos seguros privados de saúde, expressa a determinação do Estado de fortalecer sua capacidade de intervenção nessas áreas, e resulta necessariamente em demandas por novos conhecimentos científicos.

Apesar dos limites dos financiamentos para as atividades de C\&T e para as universidades e outras instituições onde a pesquisa científica e tecnológica em saúde está albergada, a comunidade científica brasileira em saúde tem ampliado a sua capacidade e produtividade e há evidências de que se encontra em expansão (Coimbra Jr., 2003). O aumento da sua capacidade de responder às necessidades dos processos de elaboração de políticas em saúde será uma conseqüência do fortalecimento dos laços entre os órgãos decisórios, legislativos, norma- 
tivos e regulatórios e os centros de investigação científica e desenvolvimento tecnológico, que contribuirá para estabelecer um novo patamar na relação entre a comunidade científica e as funções constitucionais, legais e morais do Estado no campo da saúde. Como conseqüência, poderá se ampliar a capacidade de: a) produzir conhecimentos-síntese a partir do "estoque" de conhecimentos já existente na literatura científica; b) produzir e disseminar conhecimentos originais quando os conhecimentos existentes não permitirem que decisões sejam tomadas; c) fortalecer a capacidade de avaliação do impacto das decisões, sejam elas em forma de política, legislação, norma, ação etc.

\section{Referências bibliográficas}

Abraham J \& Lewis G 2002. Citizenship, medical expertise and the capitalist regulatory state in Europe. Sociology 36(1):67-88

Acheson D 1998. Independent inquiry into health inequalities in health. Stationery Office, Londres.

Ahlbom IC et al. 2001. Review of the epidemiologic literature on EMF and health. Environmental Health Perspectives 109(Suppl 6):911-933.

Barnes DS 1995. The making of a social disease: Tuberculosis in nineteenth-century France. University of California Press, Berkley.

Barnes DS 2000. Historical perspectives on the etiology of tuberculosis. Microbes and Infection 2:431-440.

Barnoya J \& Glantz S 2002. Tobacco industry success in preventing regulation of second hand smoke in Latin America: the "Latin America" Project. Tobacco Control 11(4):305-314

Botting J 2002. The history of thalidomide. Drug News Perspectives 15(9):604-611.

Brasil 1994. Ministério da Saúde/Coordenação Geral de Desenvolvimento Científico Tecnológico. I Conferência Nacional de Ciência e Tecnologia em Saúde. Brasília.

Breilh J 1989. Epidemiologia: economia, medicina y politica. Fontamara, México.

Brent RL, Jensh RP \& Beckman DA 1991. Medical sonography: reproductive effects and risks. Teratology 44(2):123-146.

Buffler PA \& Kyle AD 1996. Regulatory reform proposals and public health. Environmental Health Perspectives 104(4):356-361.
Por seu lado, a comunidade científica de saúde coletiva deve fazer valer os princípios que, com afinco, tem historicamente defendido, pondo em prática programas de investigação que ajudem a encontrar soluções científicas a curto prazo para a resolução de diversas questões. E que, além disso, produzam conhecimentos que alimentem o debate sobre as grandes questões conceituais e teóricas fundamentais de forma a se repensar o SUS, fortalecendo abordagens que compreendam a saúde como um componente relevante da vida e da organização da sociedade, conforme preconizado na nossa Constituição.
Coimbra Jr. CEA 2003 . Desafios da produção e da comunicação científica em saúde no Brasil. Cadernos de Saúde Pública 19(1):4-5.

Cunha SS, Rodrigues LC, Barreto ML \& Dourado 2002. Outbreak of aseptic meningitis and mumps after mass vaccination with MMR vaccine using the Leningrad-Zagreb mumps strain. Vaccine 20(7-8): 1106-1112.

Exworthy M, Stuart M, Blane D \& Marmot M 2002. Tackling health inequalities since the Acheson inquiry. Policy Press, Londres.

Ezatti M, Lopea AD, Rodgers A, Vander Hoorn S \& Murray CJ 2002. Comparative Risk Assessment Colaboration Group. Selected major risk factors and global and regional burden of disease. Lancet 360:1347-1360.

Fairchild AL \& Oppenheimer GM 1998. Public health nihilism versus pragmatism: History, politics and the control of tuberculosis. American Journal of Public Health 88:1105-1117.

Frohlich KL, Corin E \& Potvin E 2001. A theoretical proposal for the relationship between context and disease. Sociology of Health and Illness 23(6):776-797.

Gandy M \& Zumla A 2002. The resurgence of disease: social and historical perspectives on the "new" tuberculosis. Social Science and Medicine 55:385-396.

Hanney SR, Gonzalez-Block MA, Buxton MJ \& Kogan M 2003. The utilisation of health research in policymaking: concepts, examples and methods of assessment. Health Research Policy and Systems 1:2. Disponível em <http://www.health-policy-systems.com/ content/1/1/2>. 
Leaf D, Verolme HJ \& Hunt WF 2003. Overview of regulatory/policy/economic issues related to carbon dioxide. Environment International 29(2-3):303-310.

Macintyre S, Chalmers I, Horton R \& Smith R 2001. Using evidence to inform health policy: case study. British Medical Journal 322:222-225.

Murphy TV et al. Rotavirus Intussuscepction Investigation Team 2001. Intussuscepction among infants given an oral rotavirus vaccine. New England Journal of Medicine 344(8):564-572.

Niessen LW, Grijseels EW \& Rutten FF 2000. The evidence-based approach in health policy and health care delivery. Social Science and Medicine 51(6):859869.

Nordstrom DK 2002. Worldwide occurrences of arsenic in ground water. Science 296:2143-2145

Ong EK \& Glantz SA 2001. Constructing "sound science" and "good epidemiology": tobacco, lawyers, and public relations firms. American Journal of Public Health 91(11):1749-1757.

Oliveira MA, Bermudez JAZ \& Souza ACM 1999. Talidomida no Brasil: vigilância com responsabilidade compartilhada. Cadernos de Saúde Pública 15(1):99 112.

Raucher RS 1996. Public health and regulatory considerations of the safe drinking water act. Annual Review of Public Health 17:170-202.

Rosentock L \& Lee LJ 2002. Attacks on science: the risks of evidence-based policy. American Journal of Public Health 92(1):15-18.
Saloojee Y \& Dagli E 2000. Tobacco industry tactics for resisting public policy on health. Bulletin of the World Health Organization 78(7):902-910.

Samet JM 2000. Epidemiology and policy: the pumple handle meets the new millennium. Epidemiologic Reviews 22(1):145-154.

Scrambler G \& Higgs P 1999. Stratification, class and health inequalities: class relations and health in high modernity. Sociology 33:275-296.

Smith AH, Lopipero PA, Bates MN \& Steinmaus CM 2002. Arsenic epidemiology and drinking water standards. Science 296:2145-2146.

Smith AH, Lingas EO \& Rahman M 2000. Contamitation of drinking-water by arsenic in angladesh: a public health emergency. Bulletin of the World Health Organization 78(9):1093-1103.

Strategic Policy Making Team, Cabinet Office, UK 1999. Professional policy making for the twenty first century. Disponível em <www.cabinet-office.gov.uk/mod erngov/policy/>.

Tesh SN 1988. Hidden arguments: Political ideology and disease prevention policy. Rutgers University Press, Londres.

United States General Accounting Office, 2001. Research and regulatory efforts on mobile phone health issues. GAO-01-545. Disponível em <www.gao.gov>.

Artigo apresentado em 8/12/2003

Aprovado em 17/2/2004

Versão final apresentada em 2/3/2004 